\title{
Modern Geodata Management: Application of Interdisciplinary Interpretation and Visualization in Central America
}

\author{
T. Damm and H.-J. Götze \\ Institute of Geophysics, University of Kiel, Otto-Hahn-Platz 1, 24106 Kiel, Germany \\ Correspondence should be addressed to T. Damm, tdamm@geophysik.uni-kiel.de
}

Received 5 September 2008; Revised 27 December 2008; Accepted 4 March 2009

Recommended by Michael S. Zhdanov

\begin{abstract}
In the last years new methods of data acquisition and processing in geosciences, inspired by growing computer performance, have led to an increased amount of data, and this development will proceed surely. In this paper we present the conception and technical realization of an interdisciplinary research group's geodata management as a combination of a metadata catalog together with web mapping technology. Clearly related with the storage and retrieval of different datasets is the need of visualization. $3 \mathrm{D}$ visualization in geoscientific interpretation is a useful tool, if numerous, heterogenic datasets have to be visualized at the same time. Moreover, advanced sensing technology often generates native three-dimensional datasets. Using a case study from the Collaborative Research Centre "SFB 574", we present the possibilities of our stereoscopic projection system and want to explain the benefit of $3 \mathrm{D}$ visualization for research in general and university education in particular, as low-cost systems become available nowadays.
\end{abstract}

Copyright (C) 2009 T. Damm and H.-J. Götze. This is an open access article distributed under the Creative Commons Attribution License, which permits unrestricted use, distribution, and reproduction in any medium, provided the original work is properly cited.

\section{Introduction}

The Collaborative Research Centre "SFB 574"-Volatiles and Fluids in Subduction Zones: Climate Feedback and Trigger Mechanisms for Natural Disasters (SFB574 [1]) —is hosted at the "Christian-Albrechts-University zu Kiel" and the "IFMGEOMAR". It is funded by the German Research Foundation (DFG) and these institutions. The center is organized in three research areas- "Subduction zone processes and structure", "Fore-arc volatile turnover and fluid flow", and "Slab-arcatmosphere transfer". These three research areas actually are represented by 13 subprojects working in different fields and with different geoscientific methods, for example, active and passive seismology, magnetics, electromagnetics, heat flow, hydration analysis, sedimentology, vent fluid and water column analysis, petrology, isotope tracers, and volcanology. As over fifty researchers are working on different geoscientific aspects of subduction processes, data management and presentation using internet technologies like web mapping is crucial for any interdisciplinary cooperation.

One prerequisite for cooperation in multidisciplinary projects is the knowledge about available data-not just for the data administration. The increasing amount of SFBs digital databases causes needs for extensive data documentation to guarantee their long-term use and avoid redundancies. As flexibility is needed in a big interdisciplinary research project (like a "Collaborative Research Center") regarding the acceptance of data formats, consistent data documentation can just be achieved by use of a well-defined (-documented) metadata catalog structure, describing main aspects of each single piece of data-either stored directly in a spatiallyenabled database or saved as a data file in specific formats.

The development of a metadata information system also facilitates the query of suitable spatial information over the internet. The most significant ability of the internet module is the presentation of new datasets from laboratory work, field research, and remote sensing together with metadata of diverse geoscientific data in a way to make it more useful to scientists but also to the interested public. Based on an earlier version (e.g., Mohr and Götze [2] or Götze et al. [3]), the actual SFB web site has been turned into a geo-service tool, which provides data, metadata, and numerical tools for 3D modeling, mapping, and visualization. This is achieved by the introduction of a metadata catalog providing detailed 
descriptions for each dataset. Coupled to this catalog is a web mapping solution based on the "UMN MapServer" project [4] from the University of Minnesota, which dynamically can plot datasets from the catalog. These two parts interact with a content management system for static page content and a database driven part for dynamic content, a seamlessly integrated web portal has been formed. As it is open to the public audience, coupling points with external researchers and other research projects can be discovered. Also efforts are made to strengthen the collaboration and data exchange with partners from the participating countries of Central America and colleagues from the US Margins program.

The authors of this paper were responsible for the collection and storage of data and laboratory information from the entire SFB 574 working groups and our research partners in a user-friendly, online environment. In particular, we, the Geoscientific Information System (GIS) group, are focusing on the construction of an easily accessible database system, visualization of different data types, statistical data research, and installation of both a GIS and a Meta Information System (MIS) for the project. The full MIS system is accessible over the internet at the SFB 574 website.

We will conclude this introduction with some general remarks on GIS specific issues. Many geoscientists, who are modeling and using GIS software, do not generally deal with geometric entities like "point", "line", "triangle", "cube", or "polyhedron". They are accustomed to think in terms of "fault planes", "rivers", "geological formations", or "increased reflectivity". Most of us like to have access to the geometry of the "Liquiñe-Ofqui-Fault" in South Chile, rather than to "lines 17 through 218". This fact leads directly to the definition of geo-objects, which may be defined as "existing geoscientific objects, composed by a name, geometry and a thematic description" (as discussed by Breunig [5]). For those users involved in complex interpretation of interdisciplinary and heterogeneous geodata, GIS methods and functions, which are based upon a geoobject data structure, become important. It is clear, that object-oriented database management will affect most of the tasks related to geosciences (3D/4D models, visualization, validation, geostatistics, and more) but still broad access to this technology in a uniform way is a bottleneck for this approach.

Geologists and geophysicists often work with objects that are composed of different geometries and parameters (e.g., temperature, pressure, petrological composition). Furthermore, they are linked to each other by complicated relations varying through time.

As an example the Mohorovičić discontinuity (Moho), is a well-known entity with a complex structure which can illustrate the mentioned problem. A "MOHO"-geo-object could be defined as follows:

(1) the lower boundary of bodies with crustal densities;

(2) a line (2D) or surface (3D) across which the p-wave velocity increases abruptly;

(3) the surface at which topography becomes isostatically balanced;

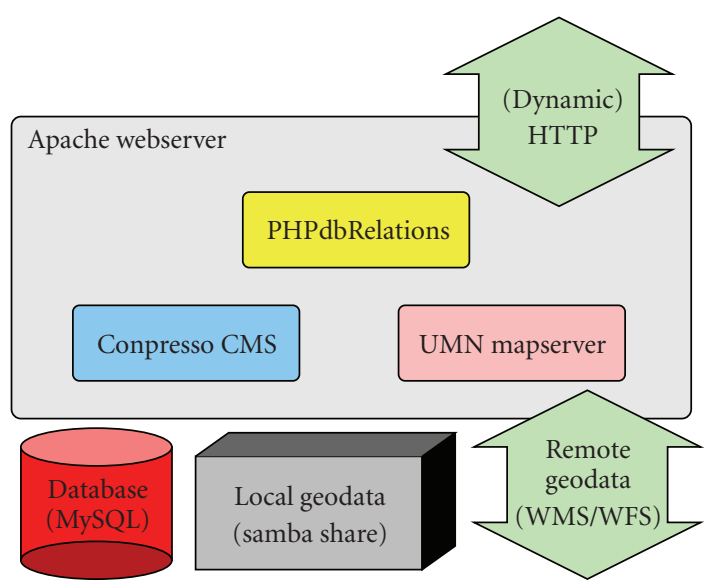

FIGURE 1: Behind the scenes of our data management. Using the apache web server [15] and a MySQL [14] database, we are using the "ConPresso Content Management System" [16] for static content. Dynamic content is managed using the PHPdbRelations toolkit [17] with its export routines for HTML and XML through PHP [18] (see also Williams and Lane [19]). For web mapping, the UMN MapServer [4] (refer also to Mitchell [20] and Erle et al. [21]) is used via the PHP/Mapscript [22] framework.

(4) the interface between rigid crustal material and weak lithospheric material.

A tool for object definition should provide the following functions:

(1) the ability to define geo-objects with composite geometry, and

(2) the ability to link several geometrically independent objects corresponding to the same geo-object.

Some of these features are implemented in the in-house software package IGMAS [6, 7] standing for "Interactive gravity and magnetic application system"; IGMAS+ is a new JAVA software and is replacing the older IGMAS software (http://www.gravity.uni-kiel.de/igmas/) which has been used for modeling both Central America and Central Southern Andes (e.g., Kösters [8], Wienecke et al. [9], Melnick and Echtler [10], Tašárová [11], Lücke [12]).

\section{Technical Requirements}

In the planning period, the formerly existing web page of the SFB 574 was analyzed and inspired by the data management of the former SFB 267 (Mohr and Götze [2], Ott et al. [13]) and their website structure, an improved concept for an integrated web portal driven by a MySQL [14] database, was developed (cf. Figure 1).

We like to mention that no commercial software was used. The "ConPresso Content Management System" [16] — free for academic use-was improved by integrating "PHPdbRelations" [17], a system, which was developed by one of authors (Damm). Essentially, it is a web-based tool for creating and modifying database tables and relations. 
Generalized export routines for web content have been programmed; for example, the queried content can be simply listed, put into tables, or sent as XML.

The content is divided into database tables with strictly defined relations between them. This might be clarified by a practical example. Let's say, Table 1 is hosting all datasets of the SFB, and Table 2 is a second one that hosts the SFB cruises in the Pacific Ocean. The relation, that a dataset was acquired on a particular cruise, might be relation number 51. Then a call to a pseudofunction PHPdbRelationsEXPORT ("Datasets_T1(Cruise_R51)") would give a list of all datasets together with the cruises undertaken to acquire these datasets. Of course, that is a simplification, as more features like filtering or sorting are implemented but in principle a call for a desired dataset results in human readable macrocode on user-level. That is the intention of PHPdbRelations.

Not just the content but also the data organization structure can be updated from the PHPdbRelations administration page. Database tables can be created or erased, columns added or removed. Furthermore the relations can be modified, if a structural change requires it. PHPdbRelations thus is not just useful for geoscientific web portals; but moreover it is a general metacontent management system dealing with single pieces of information in contrast to classical content management systems, which work pagewise.

For the implementation of the metadata catalog, the use of PHPdbRelations gives enough flexibility to adopt also existing projects to future standards without the need to migrate to other systems.

\section{Web Portal}

Implementing the PHPdbRelations toolkit into the SFB 574 website not just affected the data portal but also brought datasets into relation with their creators, the cruises, or campaigns undertaken to retrieve them or the measurement location. Even more, the same system manages all other information like seminar talks, SFB publication, and even personal data like email addresses, rooms, or telephone numbers in a structured manner. This approach allows us to keep all these different pieces of information up-to-date using one central point - the PHPdbRelations administration web page.

Moreover, this website is expanding the strict hierarchical structure implied by the usage of menus and submenus. Website-internal links bring information into their context as they break the top-bottom hierarchy. In Figure 2 an example of this website-internal linking is shown. There is no extra administrative effort anymore, for instance, to create a page for each subproject, that brings together all references corresponding to, for example, publications, meeting talks, posters presented, and datasets in the metadata catalog. For further details you can follow direct links to different parts of the website, as if you would have searched directly for the information or as if you would have followed the menu structure. Using the PHPdbRelations toolkit makes this approach possible and manageable for users.

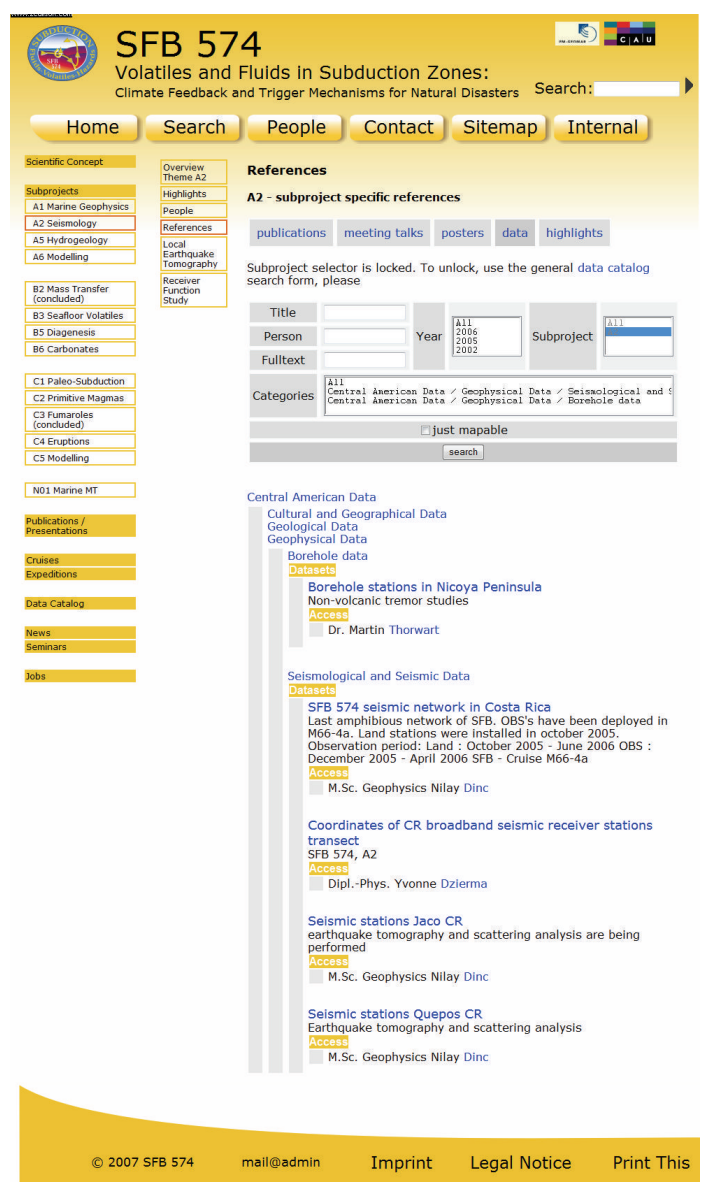

FIGURE 2: A subproject specific search form from the website of the "Collaborative Research Centre 574", which serves as a portal for information about the scientific goals of the interdisciplinary projects, the available datasets, members and partners, and much more. References to publications, presentations, posters, or data are directly linked to subprojects, as seen in this screenshot. In the same way those items are linked to people, cruises, or areas-all relationships are driven by the PHPdbRelations system [17] and served by a MySQL database [14].

\section{Data Catalog}

Central part of this project is the geoscientific data catalog. It implies a well-defined structure, which was built upon the SFB 267 data catalog [23] (also refer to Oncken et al. [24]). On a location-based level, this structure might be, for example, "Central American Data", "Andean Data", and "Global Data" followed by a structure based on geoscientific disciplines: cultural and geographical data, geological and geophysical data (e.g., grav/mag data, active and passive seismological datasets, borehole data, geodetic GPS data, remote sensing and topographic data).

Furthermore each dataset is linked to the people in charge and the related subproject(s). Additionally, the area is defined by a polygon, which can be queried using the web mapping solution. The benefit for the user is the possibility to formulate questions like "Which other datasets are available in the region of my interest?" An online search form enables specific searches for the user. If a single dataset is selected, 
further information is provided to characterize the dataset. This includes title, source, type, format, file size and name, columns, an example line from the file, producer, processor, access person, subproject responsible for the dataset, and web links and publications related to this dataset-also direct web mapping links, if the dataset is published already.

ASCII or XML/GML [25] file formats as clear type formats are highly desired as primary data format, as they promise the highest long period compatibility. The original data formats are stored in addition, in our case usually ESRI Shape files, GMT grids, and $x y z$ tabular files (e.g., csv). At the moment, already more than 100 datasets are entered into the database; more than 80 can be used for web mapping. Interoperability in the new IGMAS+ modeling software is achieved through a huge variety of interfaces and data exchange formats. Special emphasis is placed on an appropriate XML definition. The software is just under compilation in close cooperation with European oil and gas industry; so far only internal information on formats and interfaces are available at a sponsor related IGMAS-Wiki (Schmidt, pers. comm.).

Moreover, we want to point out that our working group implemented a metadata catalog in contrast to centralized data(base) storage facilities. Surely, for long-term usability, the final datasets have to be compiled and published in the last phase of the project on the website. In the outlook, we will discuss not only the problems but also the advantages of this MIS-based concept.

\section{Web Mapping}

Web mapping has developed from providing simple pictures over so called "picture maps" to dynamic web mapping applications. Geosciences represent a diverse field of investigation and caused by missing standards; many different and quite heterogeneous solutions for both data and metadata have been introduced but commonly accepted standards still have to be developed.

The Open Geospatial Consortium (OGC [26]) is supporting this process for over ten years now, of course in cooperation with the International Organization for Standardization (ISO), in particular with the technical committee 211 (ISO/TC211 [27]) responsible for "Geographic Information/Geomatics". Among others the OGC specifications web coverage service (WCS), web feature service (WFS) and web mapping service (WMS) are accepted by the majority and hence became standards for web mapping and exchange between different mapping systems. They provide a format for distributing features and maps over the internet.

As the UMN MapServer is compliant to the Web Mapping Service (WMS) and the Web Feature Service (WFS) standards, external datasets from remote hosts-usually other MapServers in the internet-can be integrated. For example, NASA's Shuttle Radar Topography Mission (SRTM [28]) and Moderate Resolution Imaging Spectroradiometer (MODIS) [29] data was integrated using this technique. Such standards greatly support interoperability in contrast to monolithic systems and expensive services; for example, data reformatting for transfer from one system to another become needless.

Still underway is the broad application of the ISO19115 standard for metadata characterization and the corresponding ISO19139 standard for the XML encoding of the metadata in combination with ISO19119 for proper definition of the service interface worked out by ISO Technical Committee 211 [27]. At the moment it seems that the possibility of using custom profiles is a weak point from a data exchange point of view (following discussion during IDEW workshop [30]).

For the SFB web portal, we integrated the UMN MapServer [4], because the availability of the PHP/Mapscript [22] interface provides simple and flexible integration. A starting point for our modifications was the php.mapper framework [31]. A direct connection to the metadata catalog was implemented; therefore users can search in the catalog for a dataset using all desired search conditions and add it to the web mapping menu. This was possible by generating a dynamic map file representation instead of a predefined, static one.

If a dataset is shown in the map, the user can search for features by a string or query an area to get a listing of all features inside his selection. In addition to this, it is possible to query an area and get all datasets from the data catalog not shown so far that overlap with the selection to find additional information about a particular area easily.

\section{3D-Visualization with a Graphic Wall}

The usage of 2D sections to represent spatially distributed data is often used in geosciences but cannot be considered as a general solution-features of the original data might be overseen or in between the arbitrary sections. As real 3D screens, which produce an object truly in space pixel by pixel, for example, on a series of transparent and stacked LCD panels, will not exist with sufficient resolution for geoscientific applications in the near future; the quite old technique of stereoscopy can help out. Especially considering the improvement of computer and graphic rendering hardware, a $3 \mathrm{D}$ stereoscopic projection system can be built up nowadays at low cost. In the following paragraph, we describe the general concept, give decision guidelines, and present our dual system consisting of a polarizing stereo projection setup and a working-place autostereoscopic display.

The profit to use advanced visualization for geoscience is indisputable. Only a few years ago, one had to construct geological bodies (salt domes, subduction zones, etc.) using foamed or transparent plastics in order to model ideas. Today's software tools allow visualization of complicate geometries on the screen and enable the interpreter/observer to interact with the model through rotation, change of viewpoint, clipping, hiding of model parts, and/or illumination.

The modern interpretation task in a complex working environment, however, makes higher demands on the software than just pretty $3 \mathrm{D}$ graphics.

(1) The flexible creation and qualitative or quantitative comparison of different kinds of maps ease the work with different data types and levels of details. 
(2) Easy and intuitive, interactive input as well as graphical modification of geometry, physical parameters, and settings of the general project environmentuser-friendliness of the graphic-handling is an essential feature of a software, which will be used by geoscientists usually not familiar with GIS software.

(3) Interoperability is achieved through a huge variety of interfaces and data exchange formats. Special emphasis is placed on an appropriate XML definition.

As soon as $1 \mathrm{D}$ and 2D data is georeferenced correctly, it can be shown together, for example, with both 3D topography and bathymetry, or with modeled or measured underground structures, for example, from density modeling, 3D seismic tomography, or receiver function analysis.

Geosciences have developed-guided by advanced in computer graphics technology-from 2D map production on paper toward 3D and even 4D modeling of complex real world structures. Often, this has led to a lack between academic education in universities and industrial needs (e.g., in the framework of oil and gas exploration) induced by historical and financial reasons.

\section{Technical Realization of Visualization}

For stereo visualization, we use a pair of stacked mainstream DLP data projectors with XGA resolution $(1024 \times 768)$ and 2500 ANSI Lumens brightness, polarizing filters, a $200 \times$ $150 \mathrm{~cm}$ silver screen and polarizing glasses (Figure 3 ). The polarizing filters are positioned in front of the two-roofmounted data projectors. They let transmit the light perpendicular polarized to each other; one emits just horizontally polarized light, the other just vertically polarized. The silvercoated screen preserves this polarization states, and hence wearing polarizing glasses, a channel separation with respect to the left and the right eye is achieved, and each eye just observes the picture of one-data projector.

The computer system used is based upon an Intel Core2Duo processor, 2 GB RAM, and a professional Nvidia Quadro FX 4500 graphics card with $512 \mathrm{MB}$ memory. We have chosen this quite expensive graphics hardware, as it allows the usage of so-called "Quad-Buffered" stereo mode required by many professional $3 \mathrm{D}$ software products like GoCAD. A 3D mouse from Connexion makes navigation easier.

For preparation and testing of 3D scenes as well as for single user $3 \mathrm{D}$ interpretation, we use an autostereoscopic display of $19^{\prime \prime}$ with a resolution of $2 \times 512 \times 768$ pixels (1024 $\times 768$ pixels standard resolution) from Dimen Technologies (Figure 4). Recent developments in display technology resulted in a possible resolution of $2 \times 960 \times 1080$, as $24^{\prime \prime}$ displays with a normal resolution of $1920 \times 1080$ become available on consumer market. Also the eye-tracking included in such screens is a big step forward, because the user can move around the 3D monitor and, with appropriate software, even see the objects from different angles. Without this tracking, movement just leads perspective distortion and the loss of the correct 3D impression.

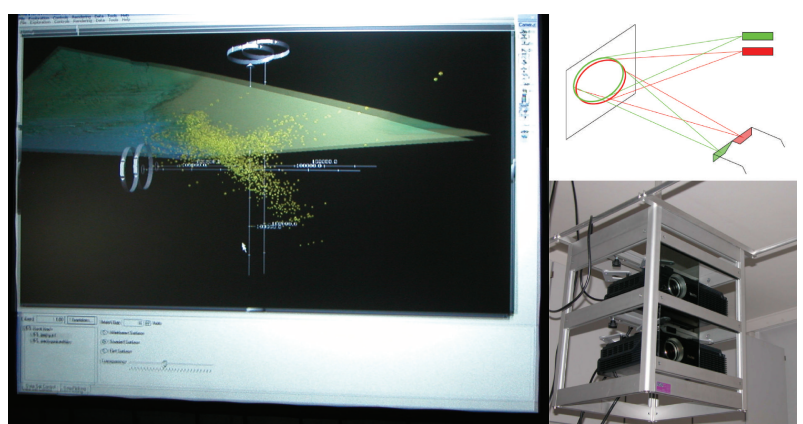

Figure 3: The low-cost 3D stereoscopic projection equipment of our working group. Two data projectors (right side of the figure) deliver two perspective views, passing perpendicular aligned polarization filters. A reflective-coated screen (left side) preserves the polarization state of each picture due to metallic reflection. Viewing through polarizing glasses, each eye just sees its distinct perspective view, and a stereoscopic depth impression is the result. Compare the simple sketch in the right upper corner, as it demonstrates the technical principle of such a Geowall setup [32].

It is important to point out that two different kinds of stereo applications exist: normal OpenGL or Direct3D stereo managed by the driver package of the graphics card vendor. In normal $2 \mathrm{D}$ mode, just one perspective view will be rendered from a particular scene. In stereo mode, the driver delivers two perspective views instead: one shifted slightly to the left, another one slightly to the right. Quad-Buffered stereo mode in contrary is managed by the application itself-for each channel distinct views of the scene are delivered to the graphics system. Two standard, doublebuffered pipes form a so-called quad-buffered stereo mode. For example, GoCAD, IGMAS+, Paraview, and Fledermaus GIS are such applications.

\section{Case Study: Subduction in Central America}

After the introduction to the technical details in the previous chapters, we will provide insight into the application of the data management system and demonstrate how to work with the different datasets of the "Collaborative Research Centre 574, SFB 574" (refer also to the introduction of the paper). Also the benefit of using our stereoscopic projection system presented so far will be demonstrated, as we combine numerous different datasets to gain new insights.

Subduction erosion shapes at least half of the world's convergent margins. However, the rates and modes as well as spatial and temporal variation are poorly understood. Based on a compilation of published and newly derived estimates of subduction erosion along the Central American margin (Ranero et al. [33], Grevemeyer et al. [34], Bundschuh and Alvarado [35]), we visualize the geometry of the Central American subduction regarding the pacific Cocos and Nazca plates below the Caribbean plate.

The following figures are snapshots from our 3D stereoscopic visualization system, and as simple printouts on paper they lose much of the depth impression. It was a serious 


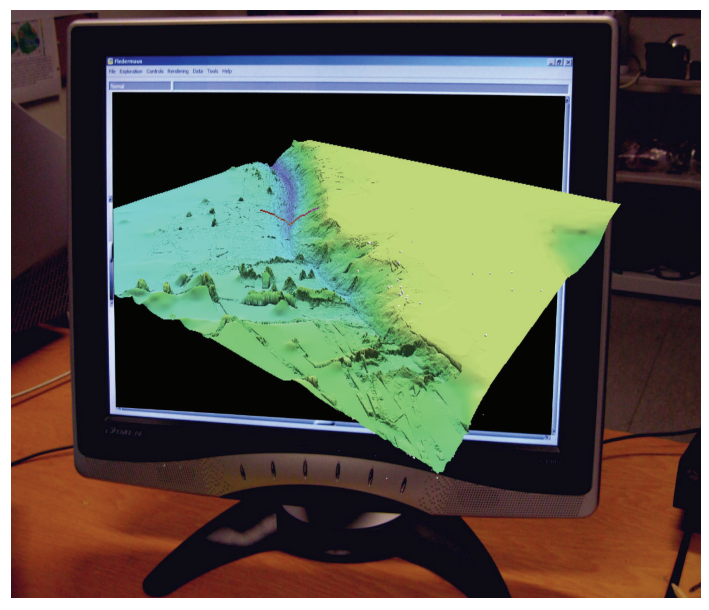

FIGURE 4: Autostereoscopic displays use optical elements in front or behind a standard liquid crystal display (LCD) to deliver a separate picture to each eye of the user without the need to wear glasses. The figure shows the bathymetric dataset of the Central American subduction zone, the deep trench, and the flat shelf area offshore Costa Rica. The screen shown is a Dimen C190S without eye tracking - the user must find and hold the correct viewing position in front of the screen.

task to produce these snapshots, always trying to get a clear perspective impression. This was done by carefully choosing the right viewpoint and reducing the number of shown features-compared with the original stereoscopic visualization it is a clear restriction and underlines the worth of advanced visualization techniques.

\section{Bathymetry and Land Surface}

Figure 5 shows the research area of the Collaborative Research Center 574 [1] on- and offshore Central America. The research until 2008 has mainly been focused on Costa Rica and partly Nicaragua. The databases behind the images are the SRTM3 topographic dataset [28] with a $90 \mathrm{~m}$ resolution and offshore the GEBCO 1-minute grid [36] with approximately. $3 \mathrm{~km}$ grid spacing. Additionally, highresolution bathymetry data collected by the SFB 574 and the IFM Geomar have been integrated.

Topography on land is characterized by two prominent mountain belts: the Cordillera de Talamanca (C-Ta) (southeast) with heights up to $3800 \mathrm{~m}$ and the recently active volcanic belt of Costa Rica (Rincón de la Vieja (RI), Miravalles (MI), Arenal (AR), Poás (PO), Irazú (IR), Turrialba (TU)). They are members of three mountain ranges, namely, the Cordillera Guanacaste $(\mathrm{C}-\mathrm{G})$, the Cordillera Tilarán (C-Ti), and the Cordillera Central (C-C).

More to the north in Nicaragua, the volcanic activities show an offset of $50 \mathrm{~km}$ eastward. The Concepción volcano (CO) is located inside the Lago de Nicaragua (LN). Later, the perspective view in Figure 11 links the volcano's geographical location to crustal domains of low seismic velocities and therefore to the presence of upcoming magma and fluids inside the lithosphere.

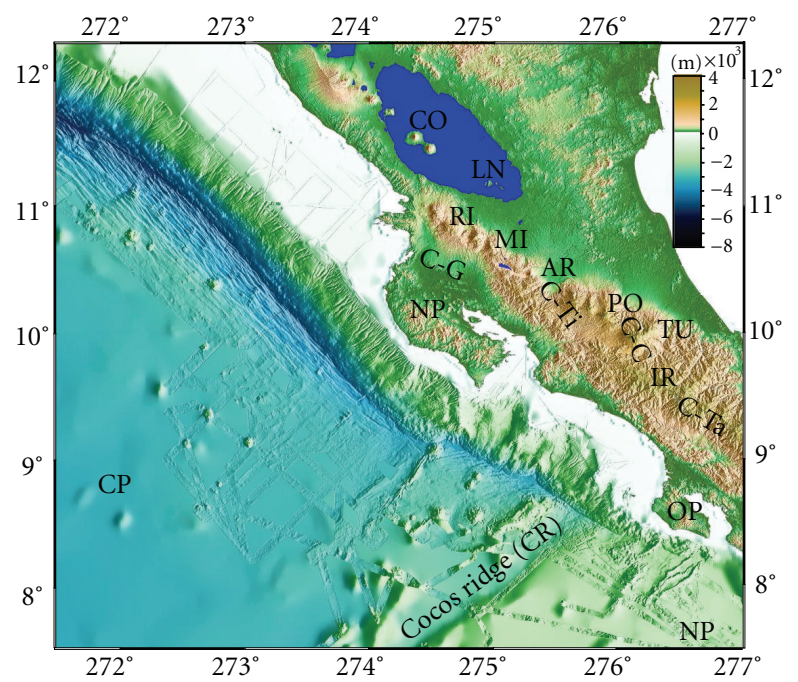

FIGURE 5: Overview map of the research area. The SRTM3 topographic dataset [28] and partly high-resolution bathymetry collected by the SFB 574 are combined. The high-resolution bathymetric data point to the dynamics of the tectonic environments and complex ocean floor bathymetry (Ranero et al. [33, 37]). The dataset was compiled from several cruises and is owned by the IfM-Geomar and the SFB 574. Some abbreviations also used in following figures are introduced: Lago Nicaragua (LN) with the Concepción volcano (CO) in Nicaragua, Nicoya Peninsula (NP), and Osa Peninsula (OP), both in Costa Rica, now from north to south: Rincón de la Vieja (RI) and Miravalles (MI) on the Cordillera Guanacaste (C-G); Arenal (AR) on the Cordillera Tilarán (C-Ti); Poás (PO), Irazú (IR), and Turrialba (TU) on the Cordillera Central (C-C) and finally the Cordillera de Talamanca (C-Ta). The Cocos Ridge (CR) collides with Central America in the southwest. (CP) stands for Cocos plate and (NP) for Nazca plate.

Offshore, active tectonic processes shape the structure of the ocean bottom, and manifestations of fluid venting and sea mounds modify the texture of the seafloor from north to south. Seafloor imaging techniques are the main methods applied in various cruises offshore Central America (Ranero et al. [37], Klaucke et al. [38]). Multiscale approaches combined shipboard multibeam bathymetry and backscatter measurements, low- and high-frequency deep-towed sidescan sonar surveys, video observations, and recordings of sub-bottom profiler and are well suited to get a rather complete image of structure and texture of the ocean floor. On its southern part, the Cocos Plate (CP) shows a rough texture covered by many sea mounds. At a clearly visible border, the bathymetry of this plate changes abruptly and becomes relatively flat (see also Figure 6). Also the trench (reaching down to $6000 \mathrm{~m}$ depth as indicated by purple colors in the north) changes at this border. In the southeast the trench not only becomes significantly shallower and generally less prominent but also changes its direction, which is obviously related to the collision of the Cocos Ridge (CR) and the Central American Land Bridge hosted onto the Caribbean Plate. Huge landslides south of Nicoya Peninsula mark this change in texture and direction. 


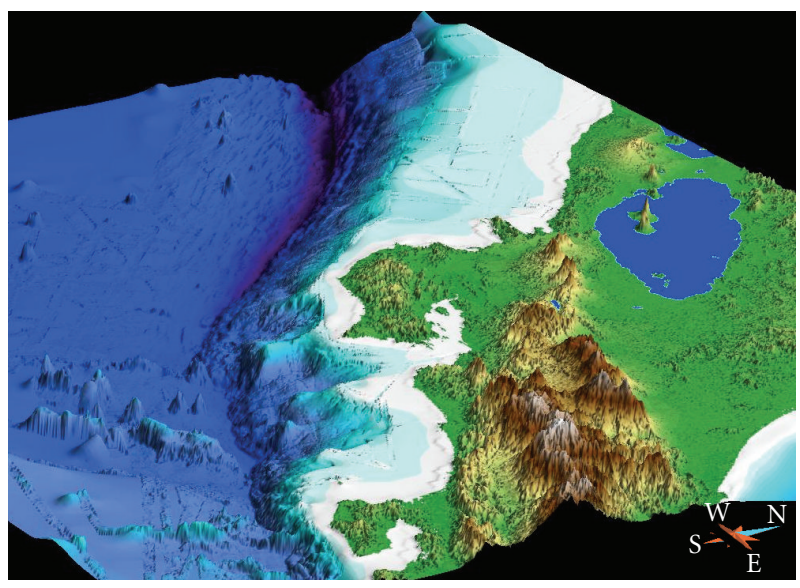

Figure 6: Perspective view onto the research area in Central America with some emphasis on the seafloor bathymetry and the trench. Looking along the trench offshore Central America in northwestern direction, in addition to the high-resolution SRTM3 topography dataset [28], we use also a lower-resolution ETOPO2v2 topography grid [39]. It surrounds the research area located inside the red bounding box covering Costa Rica, Nicaragua, and the complex oceanic floor with the incoming Cocos Ridge from southwest. The area is built by the northern portion of the Nazca plate in the south, the Cocos plate in the west, and the Caribbean plate in the east using an exaggeration of $1: 8$.

To the northwest in the outer rise area, however, faulting may rejuvenate hydrothermal circulation by reactivating and creating new faults, which may breach the sedimentary cover to allow recharge and discharge of seawater (Grevemeyer et al. [34, 40, 41], Ivandic et al. [42]). Faults that reach down to mantle depth may facilitate the migration of water down into the crust and uppermost mantle. Alteration of crustal and mantle rocks in the trench-outer rise area may therefore affect the volatile transfer of subduction zones. Refer also to Figure 7, which shows the ETOPO2 [39] dataset ( $3 \mathrm{~km} \times$ $3 \mathrm{~km}$ ) and horizontal and parallel extension faults resulting from the ocean floor bending below the continental shelf as an overlay. Here digitized faults (light green color) from the geological map of Costa Rica were draped on the lowresolution topography $\left(2^{\prime} \times 2^{\prime}\right)$ of the ETOPO2 dataset. It can be seen, especially in the stereoscopic view of our graphic wall system, that the active volcanoes are located along a lineament, which extends from the volcano Irazú to volcano Miravalles. Prominent feature is the lineament (dark pink color), which separates the Cordillera de Talamanca (southeast in Figure 7) from the active volcanoes in the northwest. This lineament joins the margin of the Caribbean plate in the NE and has regional importance, as it is part of a bigger fault system, which extends from the northern margin of the Cocos Ridge (CR) toward the Caribbean Plate. Offshore it separates the Cocos Plate (CP) in the north from the Nazca Plate (NP) in the south.

Figure 8 (top) shows the Central American topography seen from west. The dominant peak (exaggeration $1: 8$ ) is the Irazú volcano. In the north lays Nicoya Peninsula (NP). The chain of active volcanoes is separated into a northern and a

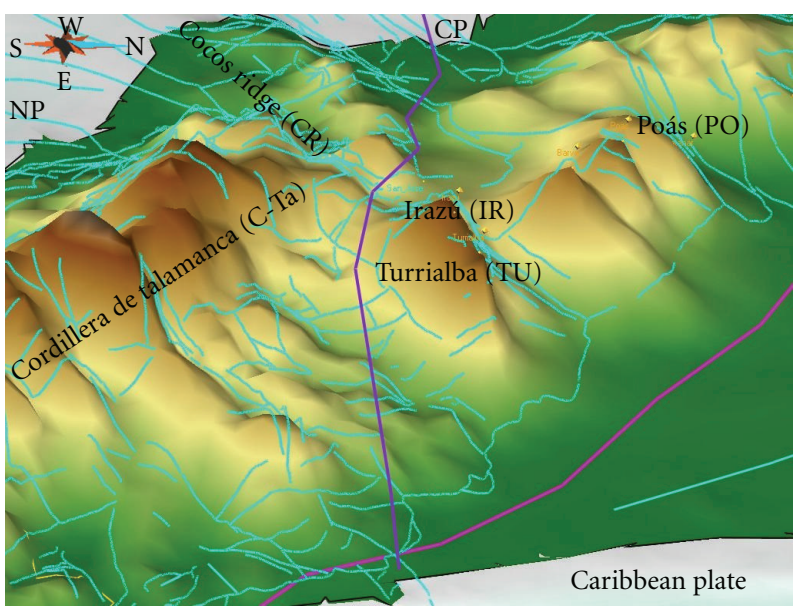

Figure 7: A perspective view from east along one of Costa Rica's main fault system. It separates the active volcanoes (east of the dark purple fault line) from the inactive volcanic Talamanca belt in the south of Costa Rica. The lineament continues to the southern tip of Nicoya Peninsula and strikes the Cocos Ridge. To visualize these lineaments, we have chosen lower-resolution topography from $3 \times$ $3 \mathrm{~km}$ ETOPO2v2 data [39].

southern subchain with the Arenal volcano (AR) in between. The southern chain is built by the edifices of Poás, Irazú, and Turrialba volcanoes forming the Cordillera Central- the northern one by Miravalles and Rincon de la Vieja located on the Cordillera Guanacaste.

In the lower part of Figure 8, we draped the geological map of Costa Rica (Tournon and Alvarado [43]) on the high-resolution SRTM3 grid [28]. The Nicoya Peninsula (NP) consists of uplifted and eroded seafloor rocks and an ophiolite complex, which crops out in smaller domains along the Pacific coastal margin of Costa Rica (marked by green colors). In the south a deep sedimentary basin with a depth of approximately $10 \mathrm{~km}$ (Alvarado et. al. [44]) shown in yellow tones is positioned in front of the older, inactive volcanic arc (purple color). In former times it was also a target for oil exploration; however no hydrocarbon was found. The Pliocene volcano chain in the east of the basin runs through Costa Rica from southeast to northwest just parallel to the quaternary, still active volcanic chain (shown in red color).

On- and offshore gravity data from various institutions (ICE, Santa Cruz; RECOPE, Santa Cruz; GETECH, Leeds) have been combined into a homogeneous dataset in Figure 9. The wealth of data was recently made available through the data portal of the SFB 574 as it was described in the first part of the paper. Due to difficult access to the high mountains, the coverage by gravity observations remains rather incomplete mainly in the area of southern Costa Rica (Cordillera de Talamanca, see Figure 7) and eastern Nicaragua. Station complete Bouguer anomalies, Free-Air anomalies, and isostatic residual anomalies maps were compiled as a result of the homogenization of gravity field data. Blending the various gravity anomaly compilations and the geological map of Central America, we already found correlations between anomalies and geological structures. 


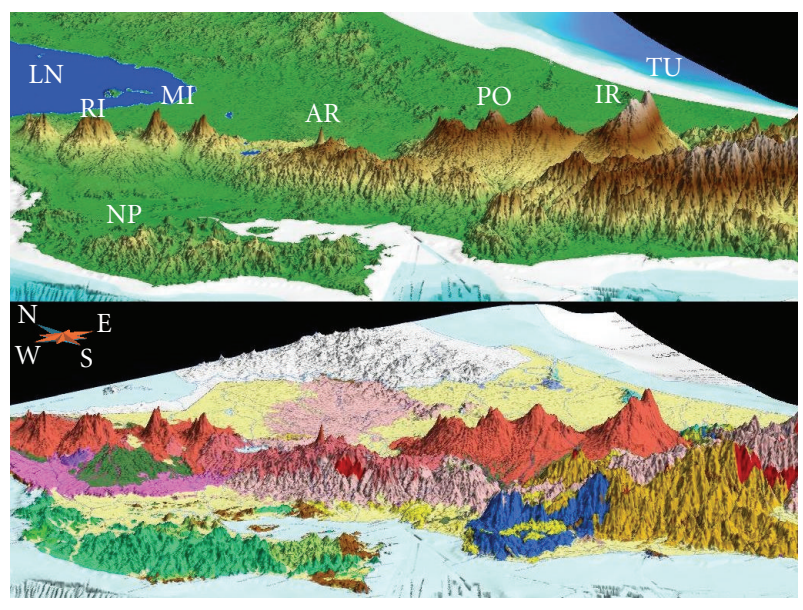

FIgURE 8: In the upper box the surface of Costa Rica and the coast near the shelf is viewed from the west using SRTM3 topography data [28]. To the northwest, Lago Nicaragua (LN) is shown in blue. The geological map of Costa Rica (Tournon and Alvarado [43]) was draped onto the topography in the lower part of the figure. Intensive red colors indicate the volcanic arc of Costa Rica with the most active volcanoes in the circum-pacific margin. The ophiolite complex of the Nicoya Peninsula is shown in dark green, and sedimentary formations and rocks are displayed in light and dark yellow tones. Dark blue marks basalt.

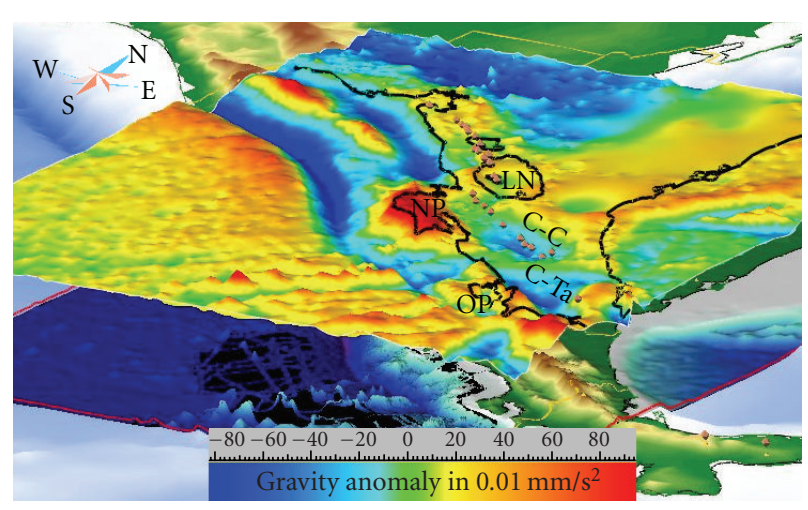

FIGURE 9: The Bouguer anomaly onshore is portrayed together with Free-Air anomaly (offshore) in the area of Costa Rica and Nicaragua looking from southeast. Most prominent features are the positive anomaly on Nicoya Peninsula (NP), which is caused by the high density ophiolite complex and gravity lows in the basin west of the Talamanca area. The gravity anomaly is pictured in exact the same area of the high resolution topography, as presented before in Figure 5. For more details refer to the text.

Dip curvature analysis of isostatic residual gravity shows that elongate zones of maximum curvature correspond remarkably well with the structural grain defined by firstorder folds and faults (Figure 7). A comparison with the geological map (Figure 10) shows a good correlation with the tectonic units and different rock complexes in most of the region and provides possibilities for crustal segmentation due to their different rock densities which cause the pattern of positive and negative gravity field anomalies.

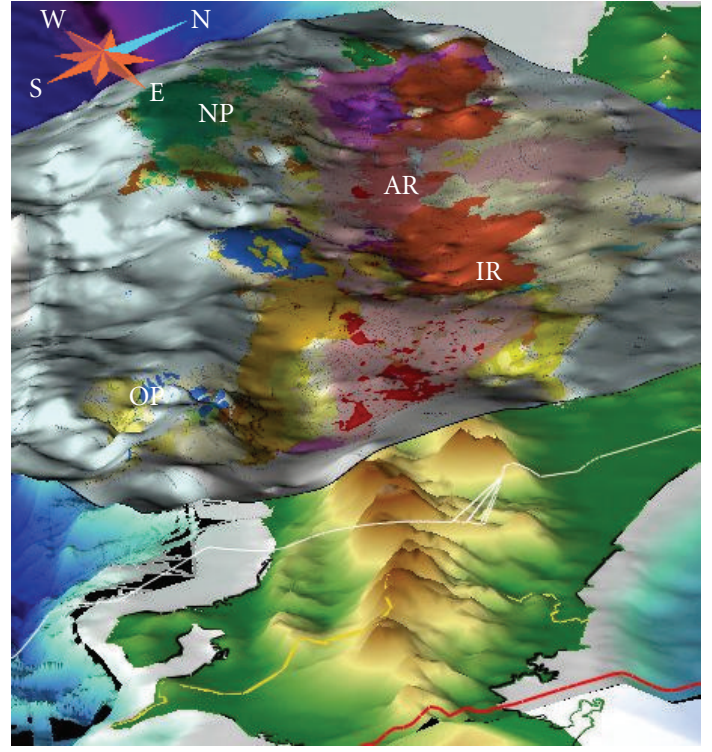

FIGURE 10: Looking from southeast, we draped the geological map of Figure 8 (bottom) onto the Bouguer gravity map (FreeAir anomaly offshore and Bouguer anomaly onshore, Figure 9). This combination provides interesting insight into the "geological" masses that cause the anomalies of the gravity field. For example, the ophiolite of the Nicoya complex, forming the Nicoya Peninsula (NP), is located in the area of the uplifted gravity field map. The active volcanic belt, for example, Irazú (IR) and Arenal (AR), in this figure is clearly located in a minimum of the Bouguer gravity field, which points to low densities in the upper crust.

In Figure 9, we show the station complete Bouguer gravity as a "flying carpet" over the topographic data. The coast lines (black) provide a better orientation, and negative offshore Free-Air gravity anomalies mark the trench dominantly. Both anomalies and trench disappear in the neighborhood of the Nicoya Peninsula (NP). Its high-density rocks cause a strong positive anomaly, as it is composed by old oceanic material and the ophiolite complex (red tones of the gravity anomaly map. Onshore the gravity lows of the Cordillera Central (C-C) in the north and the Cordillera Talamanca $(\mathrm{C}-\mathrm{Ta})$ in the south are obvious, separated by the lineament reaching "neutral" gravity anomaly (small band of green color), roughly following the land crossing fault system already explained in Figure 7.

If the geological map-compare Figure 8, lower part-is draped on the highs and lows of the gravity anomaly map (Figure 9), this combination results in a rather interesting overlay presented in Figure 10. It is shown again as a "flying carped" above the topography.

Regarding the visualization of surface structures, the possibility to combine datasets with different resolution in various ways always with exact spatial relationship to each other is a clear advantage of this system. Especially advanced methods of combining datasets like draping geology or gravity onto topography deliver fruitful new insights into complex problems. 


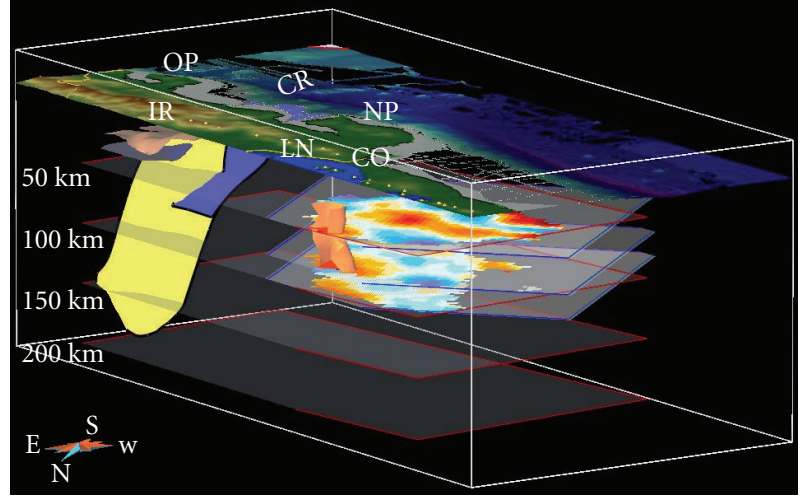

Figure 11: Perspective view from the north into the Central American lithosphere down to a depth of $200 \mathrm{~km}$ as it resulted from receiver function analysis (Dzierma $[45,46]$ ) and seismic tomography (Dinc-Akdogan et al. $[47,48]$ ). On top of the viewing box the surface topography on- and offshore is portrayed. The downgoing slab of the Nasca Plate (yellow color) and some other interfaces of lithospheric boundaries based on receiver function analysis are presented in the southeastern region below Costa Rica. Distribution of Vp velocities (at depths of 50, 80, and $100 \mathrm{~km}$ ) bases on tomographic investigations are presented in the northwerstern region below the Lago Nicaragua (LN). A low-velocity domain (orange colors) points to ascending magmatic material, which feeds the Concepción volcano (CO). For more details refer to the text.

\section{Subsurface Modeling and Visualization}

In the following part we will focus on the underground structures, which result from active and passive seismic studies, remote sensing techniques, and joint density modeling of datasets, which were compiled by members of SFB 574/subproject A2.

Figure 11 shows results of seismological studies. The subduction slab (southeast, below Costa Rica) was compiled from a 3D tomography study in the upper part of the lithosphere (blue color) and receiver function analysis in the lower part of the image (yellow color). The angle of subduction appears steeper than expected due to exaggeration. For better orientation we added horizontal planes (light grey colors) in depths of $50,100,150$, and $200 \mathrm{~km}$. In the northwest, 3D tomography results below the Lage de Nicaragua (LN) are shown.

In Costa Rica, the principal underground structure in a "subduction factory", the subduction slab, has been composed by 3D seismic tomography results at shallower depths down to approximately. $70 \mathrm{~km}$ (Dinc-Akdogan et al. [48], Dzierma et al. [45]). With the aid of receiver functions analysis, the slab can be modeled even deeper than $150 \mathrm{~km}$. In these studies a steep subduction angle of $\sim 60^{\circ}$ is observed, which is significantly different to the slab inclination of $45^{\circ}$ proposed in literature so far (Dzierma et al. [45], Dzierma [46]).

Additionally, in Nicaragua, the 3D tomography modeling bears exiting insights in the volcanic system of Central America; a chimney-like structure originating from a depth of approx. $100 \mathrm{~km}$ is located exactly beneath the Concepción

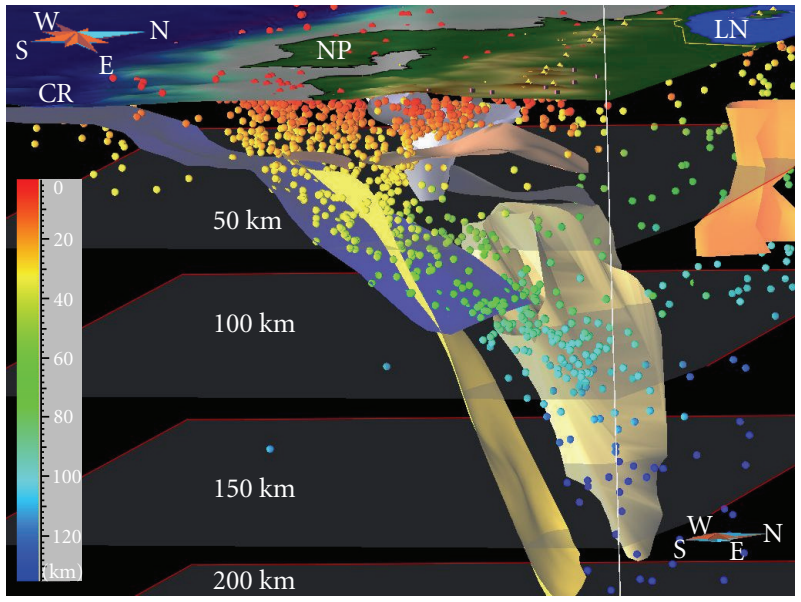

FIGURE 12: Looking roughly from southeast along the subduction zone with the slab below Costa Rica, the earthquake hypocenters from local networks of SFB 574 subproject A2 for a 6-month period are shown as balls. Not only are they distributed on the modeled slab but also they form an approximately. $45^{\circ}$ channel in direction to the volcanic chain. The red-bordered gray surfaces are $50 \mathrm{~km}$ separated from each other for orientation in space.

volcano (CO) in the Lago de Nicaragua (LN). The orange tones mark domains of low $\mathrm{Vp}$ values, and obviously this new observation reflects the existence of "hot" magmatic material - at least a higher content of fluids-in depths between the Earth's surface and the depth of $100 \mathrm{~km}$.

To verify the geometry of the modeled slab, the seismological events (earthquakes hypocenters) received from local seismological networks during six monthes have been integrated into Figure 12. As expected, they verify the model geometry and are mainly positioned onto the proposed slab geometry. The different colors of the small "balls" indicate the depths. Again, the "chimney", already visualized in Figure 11, is shown here in the perspective view and in relations to the colored hypocenters. It leaves the slab from a depth of approximately. $100 \mathrm{~km}$ and leads to the volcanic chain with a slope of $\sim 45^{\circ}$. In the interpretations of DinkAkdogan [48] and Dzierma [46], this structure is related with fluid pathways driving induced melting and hence triggering volcanic activity.

Using our in-house modeling software IGMAS, a 3D density model (Figure 13) could be compiled in the area of Central America, taking into account various results and models of seismic research (Figures 11 and 12) as constraining information about the principal slab geometry (Dzierma [46], Dzierma et al. [45], Dinc-Akdogan et al. [48], Thorwart, pers. comm.). Evenmore, for the first time a 3D density model has been accomplished (Lücke [12], see Figure 14) by combining the results of curvature analysis and Euler deconvolution together with other constraining data from geological maps covering the surface of the model, structural information from older seismic profiles and earthquake hypocenters. Both models are presented in the next paragraphs. 


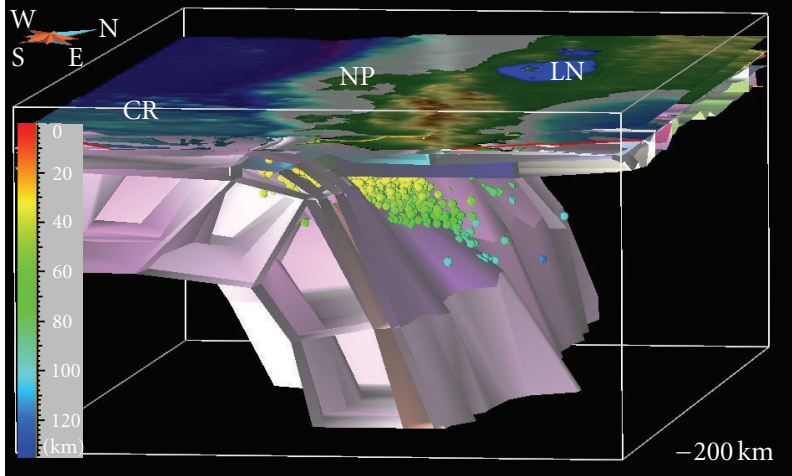

Figure 13: The 3D density model is compiled by the IGMAS software $[6,7]$. It is constrained by the seismological information displayed in Figures 11 and 12. The model is seen from the southeast together with the hypocenters and the DEM as surface. The model dips down reaching a depth of $200 \mathrm{~km}$. It was mainly compiled by V. Giszas.

In collaboration with the seismological research group (subproject A2 of the SFB 574), the new tomographic results were taken to constrain the larger, regional model of Central America. Velocities were converted into densities following an approved method of Sobolev and Babeyko [49] (see also Hacker and Abers [50]) and assuming typical gradients of temperature and pressure conditions in volcanic areas. Therefore, the 3D density model provides a synoptic picture of the investigated area down to the upper mantle. It can help to identify the border between larger tectonic blocksfor example, the Chortis block in the north or the Chorotega block in the south. The modeling was used to visualize the gravity effects due to serpentinization of oceanic lithosphere at the Pacific side.

At a more local scale, our 3D modeling provides insight into the upper crustal parts under the volcanoes of Central Costa Rica. Surprisingly, the area of the central volcanic chain in Costa Rica is covered by negative Bouguer anomalies, whereas further to the north the volcanic chain is located in an area with positive anomalies. This suggests a different composition of crust, that causes regional density anomalies in both areas. This should also be reflected by different seismic velocities.

In combination with the regional model (Figure 13), also a quite local and shallow density model of Costa Rica (presented in Figure 14) has been modeled using lGMAS gravity modeling software (Lücke [12]). It is presented together with solutions from Euler deconvolution analysis (Pašteka [51]). This model consists of 3 main bodies: the red one belongs to the active volcanic chain mentioned before, whereas the two bodies along both sides (gray and light red) reflect gravity anomalies following inactive pale arcs laying west and east, respectively.

Using Euler deconvolution, this shallow gravity model could be constrained to source depths of density anomalies in the lithosphere. For this kind of three-dimensional point distribution, the stereographic visualization method can lead to new insights, as the complexity can be really "seen".

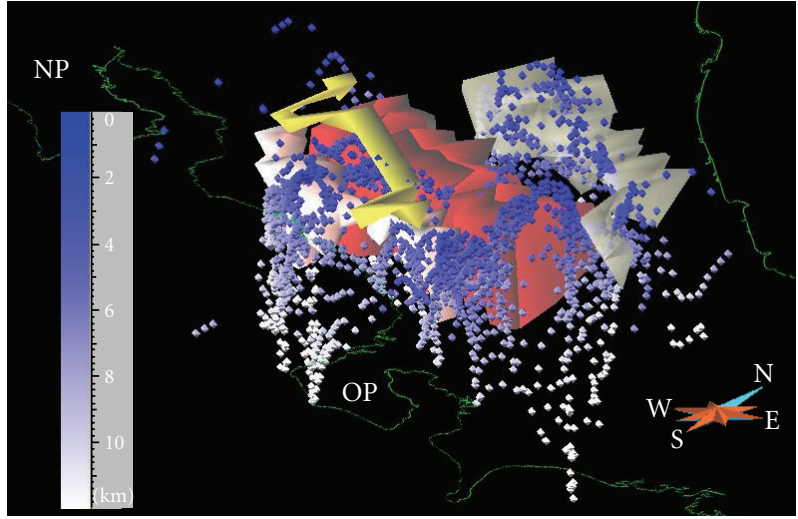

Figure 14: A second model was compiled by Lücke [12] and aimed to model the upper crustal density domains in the area of the active volcanic arc of Costa Rica. The structure in the center (red color) causes the gravity deficit beneath the volcanic arc. The depth-coded "points" (from blue to white) represent the source points of Euler deconvolution (Pašteka [51]). They are calculated independently from the gravity modeling and can help constraining the 3D model.

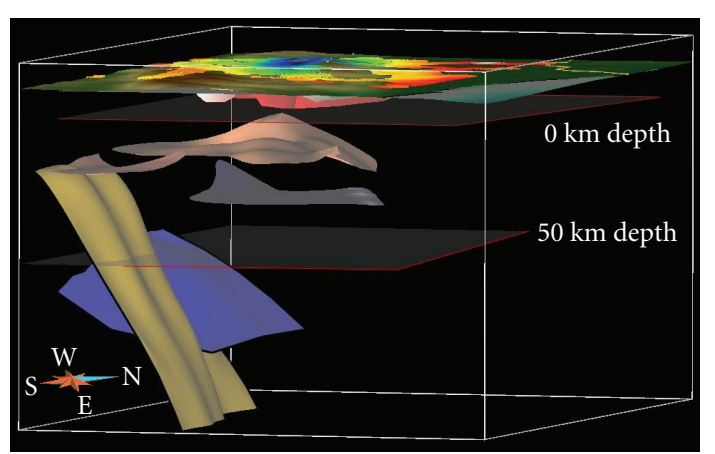

FIGURE 15: A perspective view of the geophysical interfaces compiled from seismic and gravity modeling from east. On top, the Bouguer gravity field is displayed, shifted up $20 \mathrm{~km}$ together with bodies from Lücke's local density model. Below, the down-dipping plate and other interlithospheric interfaces of the Central American crust-mantle system from 3D tomography and receiver function analysis are shown. They were displayed for joint interpretation at our Geowall [32].

The process of finding clusters and tracing them down to improve model geometry can be achieved much better than using the classical approach of vertical profiles showing just projections of $3 \mathrm{D}$ features.

In Figure 15 the results of seismic modeling from receiver function analysis and tomography are combined with the modeled "local" density structures of Lücke [12] (shifted up $20 \mathrm{~km}$ over surface level). An interesting aspect can be visualized here: Lücke's modeled "volcanic root" is placed right exactly over a thickened crust above the Mohorovičić discontinuity (grey surface from receiver function analysis). The thickened crust is shown by the light pink upwelling surface. One may speculate that this updomed structure is also related to magmatic processes and reflects interactions 
between the recent volcanic arc and lower crustal/upper mantle magmatic reservoirs.

Especially for underground structures, where the depth information is more than just one more attribute, stereoscopic visualization brings realistic geometric relationships. Modeled bodies, surfaces, lineaments, and point datasets can be drawn into the third dimension and do not "fall back" onto a sheet of paper. Unfortunately for the reader, we had to replace this by color-coded depth in most figures.

\section{Outlook}

The big task to improve efficiency in geodata management is the broad application of general accepted standards. XMLbased frameworks like, for example, the Geography Markup Language (GML [25]) are already used widely and replace storage in raw data files. As such structures are using clear text representation in conjunction with carefully named XML tags, they might be partly self-explaining to future users - in contrast to pure number tables or even binary files.

Using techniques like OGC's WMS/WFS/WCS, it is possible to build up a network of geodatabases. Management and access can be distributed, so scientists can concentrate on interpretation and interdisciplinary cooperation instead of juggling around with different data sources, formats, and projections. The "borders" between different GIS solutions, sometimes even introduced by intention out of commercial interests, can be vanished by building them against general accepted formal standards, if these standards become strict enough regardless of multidisciplinary context.

Meetings to define the current status of (meta)data standardization and further needs to improve global data exchange like the "International Data Exchange Workshop" (IDEW [30]) can help to further improve and implement already well-prepared standards.

In contrast to the presented metadata catalog describing datasets not harmonized in general, several projects aim to collect, store, and harmonize all available data right from the beginning in a centralized database driven GIS storage system (Thomsen, pers. comm., Schirnick, pers. comm.). The work flow acquiring, managing, and processing data could be more structured, as such systems will not just be used as data storage for final datasets but replace locally saved files at all working stages. Versioning capabilities will avoid data loss and allow to check every single processing step. Probably most important, filling a metadata catalog no longer represents deterrent overhead but is carried out inherent by the system, as it just accepts datasets with a proper metadata definition.

Considering the web mapping at present, a free 3D GIS visualization should replace the 2D cartographic web mapping available nowadays to truly visualize $3 \mathrm{D}$ structures over the World Wide Web. This can be realized for case studies using Shockwave or similar technologies but a general approach including standard protocols should be initiated to overcome the restrictions of the image delivery approach. In this context, also object-oriented database systems using a standard for 3D models or at least common interfaces for exchange of data are required.
The presented 3D stereoscopic visualization system is a great tool for interpretational tasks. It is a great advantage to see depth information realistically and use color and brightness for additional information. Especially, point and line data become visible in space. The technique of using cutting surfaces and project data onto such $2 \mathrm{D}$ elements distorts true $3 \mathrm{D}$ recorded datasets. Usage of shadows to achieve a perspective impression is also limited and reduces the usability of colors and the level detail. A 3D visualization system can represent more parameters more realistically at the same time.

The system presented in this paper is a low-cost geographic wall. For visualization, improvements to the projection system could be advanced data projectors with increased resolution $(1920 \times 1080)$ and brightness $(>3000$ ANSI Lumens). Also other filter systems for the stereoscopic projection could result in better channel separation and usability (e.g., Infitec filters do not base on polarization but on a spectral band pass). The combination of several screens to one, surrounding the viewer by $270^{\circ}$, or the use of a spherical screen with special optical lenses would bring our one screen projection system nearer to industrylevel 3D caves, where more information can be shown to the investigating scientists at the same time. Also head mounted displays (HMDs) could become an option for joint interpretation. Using one projection system, just one perspective can be calculated at one time. If every user would wear an HMD, a personal view (based on the tracked location of the person in the room) could be calculated. More people could walk around the "virtual" model in the middle of the room, and everybody would see the particular aspect of the model.

Regarding the user interaction, devices like head tracker or cyber gloves can be combined to let the scientist touch and naturally move or rotate objects. The head tracking system would give the scientist a very realistic impression of the objects, as the perspective is calculated according to his or her position. With a hand control unit (cyber glove), it would be possible to control the virtual universe in a natural, rapid way. Models could be moved, rotated, or sliced easily. In contrast to the head tracking system, which is compatible to most scientific software products, the cyber glove needs special interfaces to interact with software. Our new in-house product IGMAS+ will be compatible to both systems. Both approaches not only lead to a more realistic "virtual" reality in $3 \mathrm{D}$ but also and more important turn a cinema-like 3D visualization project into a tool with user-friendly, rapid, realistic, and natural control.

\section{Conclusion}

The management of complex, diverse, and sometimes huge amounts of geoscientific data is not just a question of storage. The usage of metadata and the connection to dynamic mapping makes it possible in particular for scientists working in an interdisciplinary research environment not just to manage their own data but also to undertake joint interpretation by integrating data from other geoscientific methods as problems become complex. 
The metadata catalog presented here is capable of managing diverse datasets and presenting them in a structured form to the internet audience. The level of website internal linking is tremendously increased, giving the user the best chance to find what he is interested in. Nevertheless a particular type of content is always presented inside its own context. Especially the possibility of supporting or even initiating cooperation with researchers outside this research project is one of the biggest aims. It is also possible for local institutions and agencies from Central America not only to see available data from this project but moreover to insert also their (meta)data to complete the collection and hence implement a central data portal. As the data is not available for download usually, the person in charge of the dataset can be contacted. So misinterpretation of data can be avoided and cooperation supported in contrast to a pure download link. Of course, in the final period of the Collaborative Research Center's work, a compilation of datasets must be prepared to guarantee long-term availability of the results.

The presented case study brings together datasets from different geoscientific disciplines, some are distributed in space, some on vertical sections and others just define a position, for example, volcanoes on the surface. By georeferencing them, they become comparable, not just qualitatively but also quantitatively.

As it is not possible to bring the stereoscopic depth impression to the reader of this printed journal, the difference between "guessing" the depth structure by turning around a model in a 3D data viewing software and the effect of really "see" the separation of objects along the viewing axis must be experienced and surely aid to the understanding of complex spatial relationships.

As many features are presented simultaneously to the audience, stereographic visualization brings more clarity or, let us say, more "space". In a collaborative research environment, this can be a catalysator for joint interpretation and critical analysis of results taking into account diverse other datasets otherwise probably just considered in a more or less qualitative way.

The used system is, unlike systems many years ago, based entirely on mainstream hardware. It works together with either Linux or Windows and is compatible to many available software products developed in the last years. Because programming languages like $\mathrm{C}++$ or JAVA have already implemented the rudimentary routines into their $3 \mathrm{D}$ visualization classes, it is usually a simple task to enable stereoscopic visualization from recent 3D geoscientific software products.

\section{Acknowledgments}

The authors express their gratitude to their colleagues $\mathrm{N}$. Dinc-Akdogan, Y. Dzierma, M. Thorwart, W. Rabbel, and W. Weinrebe (members of the SFB subprojects A1 and A2) who let their newly compiled datasets for their visualization and for inspiring the authors to compile appropriate visualization scenarios. O. Lücke, who has recently completed a diploma thesis in Costa Rica and worked partly in Kiel, gave a lot of insights into the Central American geological and geophysical setup. V. Giszas did a great recompilation of the $3 \mathrm{D}$ gravity modeling. The authors also like to thank two anonymous reviewers for their valuable comments on a former version of the manuscript. Also the cooperation with C. Schirnick to plan future data catalog handling was important for this project. This work was supported by the Deutsche Forschungsgemeinschaft (German Research Foundation) and is a publication of SFB 574.

\section{References}

[1] SFB574, Sonderforschungsbereich 574, CAU Kiel / IFM Geomar, December 2008, http://www.sfb574.uni-kiel.de/.

[2] S. Mohr and H.-J. Götze, "The "Central Andes GIS", a comprehensive database for studies of deformation processes in the Central Andes," December 2008, http://www.agu.org/ eos_elec/96350e.html.

[3] H.-J. Götze, M. Alten, H. Burger, et al., "Data management of the SFB 267 for the Andes-from ink and paper to digital databases," in The Andes-Active Subduction Orogeny, Frontiers in Earth Sciences, vol. 1, pp. 539-557, Springer, Berlin, Germany, 2004.

[4] MapServer, University of Minnesota, MapServer, December 2008, http://Mapserver.gis.umn.edu/.

[5] M. Breunig, Integration of Spatial Information for GeoInformation Systems, Springer, Berlin, Germnay, 1996.

[6] IGMAS Integrative Gravity and Magnetic Application System, former release documentation, December 2008, http://www .eageseg.org/data/egm2007/Sessione\%20D/Poster\%20papers/ D_PP_06.pdf.

[7] IGMAS+ 3D Gravity, FTG and Magnetic Modeling: the new IGMAS+ Software (abstract), EGM 2007, International Workshop, Innovation in EM, Grav and Mag Methods: a new Perspective for Exploration, Capri, Italy, December 2008, http://www.eageseg.org/data/egm2007/Sessione\%20D/ Poster\%20papers/D_PP_06.pdf.

[8] M. Kösters, 3D-Dichtemodellierung des Kontinentalrandes sowie quantitative Untersuchungen zur Isostasie und Rigidität der Zentralen Anden (21 $\left.-26^{\circ} \mathrm{S}\right)$, Ph.D. dissertation, Berliner Geowissenschaftliche Abhandlungen, Berlin, Germany, 1999.

[9] S. Wienecke, C. Braitenberg, and H.-J. Götze, "A new analytical solution estimating the flexural rigidity in the Central Andes," Geophysical Journal International, vol. 169, no. 3, pp. 789-794, 2007.

[10] D. Melnick and H. P. Echtler, "Morphotectonic and geologic digital map compilations of the South-Central Andes $\left(36^{\circ}-\right.$ $\left.42^{\circ} \mathrm{S}\right)$," in The Andes-Active Subduction Orogeny, O. Oncken, G. Chong, G. Franz, et al., Eds., pp. 565-568, Springer, Berlin, Germany, 2006.

[11] Z. Tašárová, Gravity data analysis and interdisciplinary $3 D$ modelling of a convergent plate margin (Chile, $36^{\circ}-42^{\circ} \mathrm{S}$ ), Ph.D. dissertation, Freie Universität, Berlin, Germany, 2005.

[12] O. Lücke, Modelo tridimensional de densidades de la corteza superior en el sector Central de Costa Rica, basado en interpretación del campo gravimétrico, Diploma thesis, Ciudad Universitaria Rodrigo Facio, San José, Costa Rica, 2008.

[13] N. Ott, H.-J. Götze, S. Schmidt, H. Burger, and M. Alten, "Meta geo-information system facilities use of complex data for study of Central Andes," EOS, vol. 83, no. 34, 2002.

[14] MySQL database, MySQL AB, USA, December 2008, http:// www.mysql.com/.

[15] Apache, "The Apache Software Foundation (ASF)," Delaware, USA, December 2008, http://www.apache.org/. 
[16] ConPresso, Bartels Schöne GmbH \& Co. KG, December 2008, http://www.conpresso.de/.

[17] T. Damm, PHPdbRelations, December 2008, http:// phpdbrelations.sourceforge.net/.

[18] PHP Hypertext Prepocessor, The PHP Group, December 2008, http://www.php.net/.

[19] H. E. Williams and D. Lane, Web Database Applications with PHP and MySQL, O'Reilly, Sebastopol, Calif, USA, 2004.

[20] T. Mitchell, Web Mapping Illustrated, O'Reilly, Sebastopol, Calif, USA, 2005.

[21] S. Erle, R. Gibson, and J. Walsh, Mapping Hacks, O'Reilly, Sebastopol, Calif, USA, 2005.

[22] PHP/Mapscript, DM Solutions Group, December 2008, http://www.maptools.org/php_mapscript/.

[23] SFB267, "Deformation Processes in the Andes," FU Berlin, TU Berlin, GFZ Potsdam, U Potsdam, December 2008, http://www.fu-berlin.de/sfb/sfb267/.

[24] O. Oncken, G. Chong, G. Franz, et al., Eds., The Andes-Active Subduction Orogeny, Frontiers in Earth Sciences, Springer, Berlin, Germany, 2006.

[25] GML Geography Markup Language, December 2008, http:// www.opengeospatial.org/standards/gml/.

[26] OGC, Open Geospatial Consortium, December 2008, http:// www.opengeospatial.org/.

[27] ISO/TC 211 International Organization for Standardization's technical committee 211, "Geographic Information/ Geomatics,” December 2008, http://www.isotc211.org/.

[28] SRTM3 Version 2, Courtesy NASA/JPL-Caltech, December 2008, http://www2.jpl.nasa.gov/srtm/.

[29] MODIS Moderate Resolution Imaging Spectroradiometer, December 2008, http://modis.gsfc.nasa.gov/.

[30] S. Carbotte, K. Lehnert, W. Weinrebe, and S. Tsuboi, "Building a global data network for studies of earth processes at the world's plate boundaries," in Proceedings of the International Data Exchange Workshop (IDEW '07), Kiel, Germany, May 2007.

[31] php.mapper, Armin Burger, December 2008, http://www .pmapper.net/.

[32] The Geowall Consortium, December 2008, http://www .geowall.org/.

[33] C. R. Ranero, R. von Huene, and W. Weinrebe, "Convergent margin tectonics of Middle America: a marine perspective," in Central America: Geology, Resources and Hazards. Vol. I, J. Bundschuh and G. E. Alvarado, Eds., pp. 239-265, Taylor \& Francis, London, UK, 2007.

[34] I. Grevemeyer, A. J. Kopf, N. Fekete, et al., "Fluid flow through active mud dome Mound Culebra offshore Nicoya Peninsula, Costa Rica: evidence from heat flow surveying," Marine Geology, vol. 207, no. 1-4, pp. 145-157, 2004.

[35] J. Bundschuh and G. E. Alvarado, Central America: Geology, Resources and Hazards, Taylor \& Francis, London, UK, 2007.

[36] The General Bathymetric Chart of the Oceans (GEBCO), December 2008, http://www.gebco.net/.

[37] C. R. Ranero, A. Villaseñor, J. P. Morgan, and W. Weinrebe, "Relationship between bend-faulting at trenches and intermediate-depth seismicity," Geochemistry, Geophysics, Geosystems, vol. 6, Article ID Q12002, 2005.

[38] I. Klaucke, D. G. Masson, C. J. Petersen, W. Weinrebe, and C. R. Ranero, "Multifrequency geoacoustic imaging of fluid escape structures offshore Costa Rica: implications for the quantification of seep processes," Geochemistry, Geophysics, Geosystems, vol. 9, Article ID Q04010, 2008.
[39] ETOPO2v2, “2-Minute Gridded Global Relief Data," U.S. Department of Commerce, National Oceanic and Atmospheric Administration, National Geophysical Data Center, June 2006, http://www.ngdc.noaa.gov/mgg/fliers/06mgg01 .html.

[40] I. Grevemeyer, N. Kaul, J. L. Diaz-Naveas, H. W. Villinger, C. R. Ranero, and C. Reichert, "Heat flow and bendingrelated faulting at subduction trenches: case studies offshore of Nicaragua and Central Chile," Earth and Planetary Science Letters, vol. 236, no. 1-2, pp. 238-248, 2005.

[41] I. Grevemeyer, C. R. Ranero, E. R. Flueh, D. Kläschen, and J. Bialas, "Passive and active seismological study of bendingrelated faulting and mantle serpentinization at the Middle America trench," Earth and Planetary Science Letters, vol. 258, no. 3-4, pp. 528-542, 2007.

[42] M. Ivandic, I. Grevemeyer, A. Berhorst, E. R. Flueh, and K. McIntosh, "Impact of bending related faulting on the seismic properties of the incoming oceanic plate offshore of Nicaragua," Journal of Geophysical Research, vol. 113, Article ID B05410, 2008.

[43] J. Tournon and G. E. Alvarado, Carte geologique du Costa Rica echelle 1:500000, Notice explicative, Editorial Tecnologia de Costa Rica, Cartago, 1997.

[44] G. E. Alvarado, C. Dengo, U. Martens, J. Bundschuh, T. Aguilar, and S. B. Bonis, "Stratigraphy and geologic history," in Central America: Geology, Resources and Hazards. Vol. I, J. Bundschuh and G. E. Alvarado, Eds., pp. 345-394, Taylor \& Francis, London, UK, 2007.

[45] Y. Dzierma, M. Thorwart, W. Rabbel, E. R. Flüh, G. E. Alvarado, and M. M. Mora, "A receiver function transect through the Talamanca Range (Costa Rica)_proof of Cocos Ridge subduction," submitted to Geophysical Journal International.

[46] Y. Dzierma, A receiver function study of Southern Costa Ricaindications of steep Cocos Ridge subduction, Ph.D. dissertation, Christian-Albrechts University, Kiel, Germany, 2008.

[47] N. Dinc-Akdogan, I. Koulakov, M. Thorwart, et al., "Local earthquake tomography of CentralCosta Rica: transition from seamount to ridge subduction," submitted to Geophysical Journal International.

[48] N. Dinc-Akdogan, W. Rabbel, E. R. Flueh, and W. Taylor, "Mantle wedge hydration in Nicaragua from local earthquake tomography," submitted to Geophysical Journal International.

[49] S. V. Sobolev and A. Y. Babeyko, "Modeling of mineralogical composition, density and elastic wave velocities in anhydrous magmatic rocks," Surveys in Geophysics, vol. 15, no. 5, pp. 515544, 1994.

[50] B. R. Hacker and G. A. Abers, "Subduction factory 3: an Excel worksheet and macro for calculating the densities, seismic wave speeds, and $\mathrm{H}_{2} \mathrm{O}$ contents of minerals and rocks at pressure and temperature," Geochemistry, Geophysics, Geosystems, vol. 5, Article ID Q01005, 2004.

[51] R. Pašteka, "The role of the interference polynomial in the Euler deconvolution algorithm," Bollettino di Geofisica Teorica ed Applicata, vol. 47, no. 1-2, pp. 171-180, 2006. 

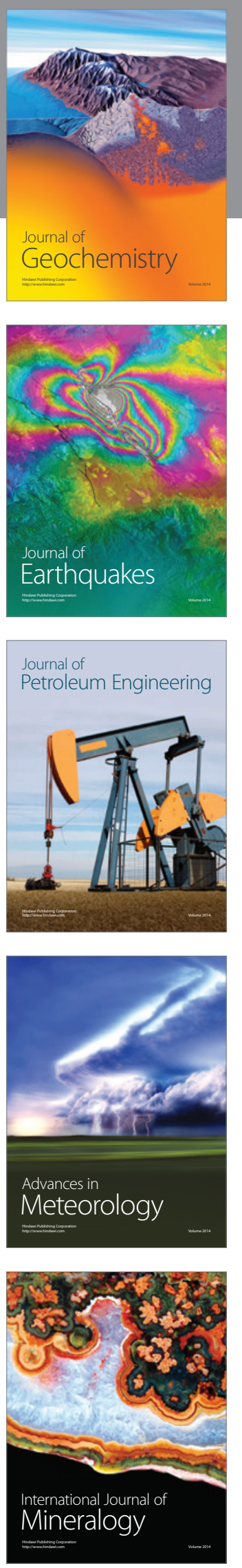
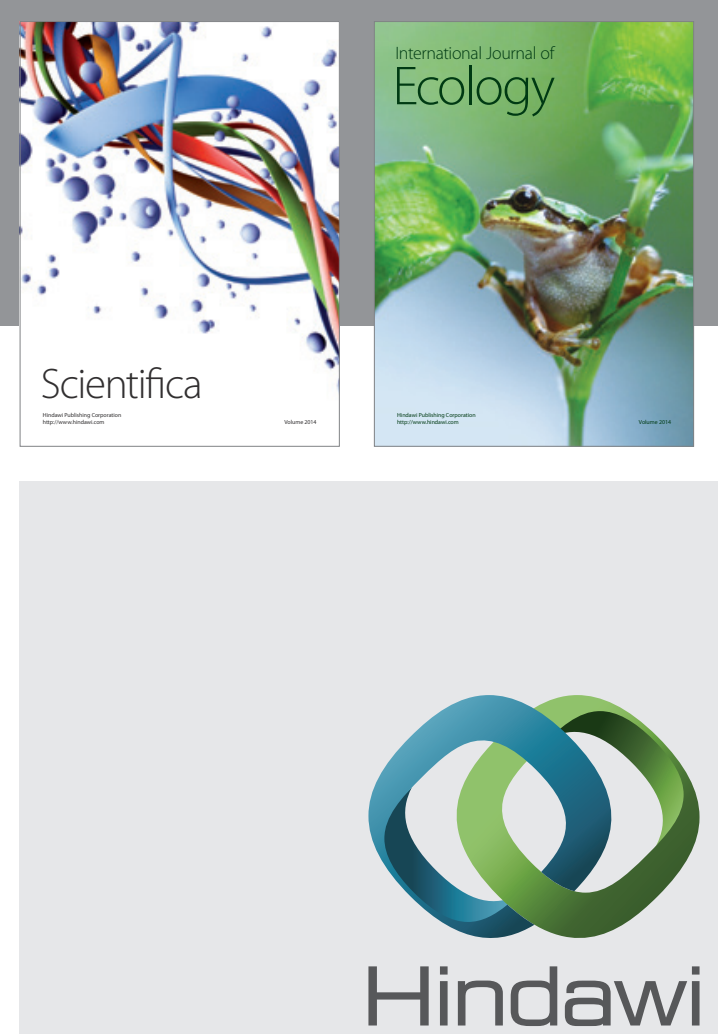

Submit your manuscripts at http://www.hindawi.com
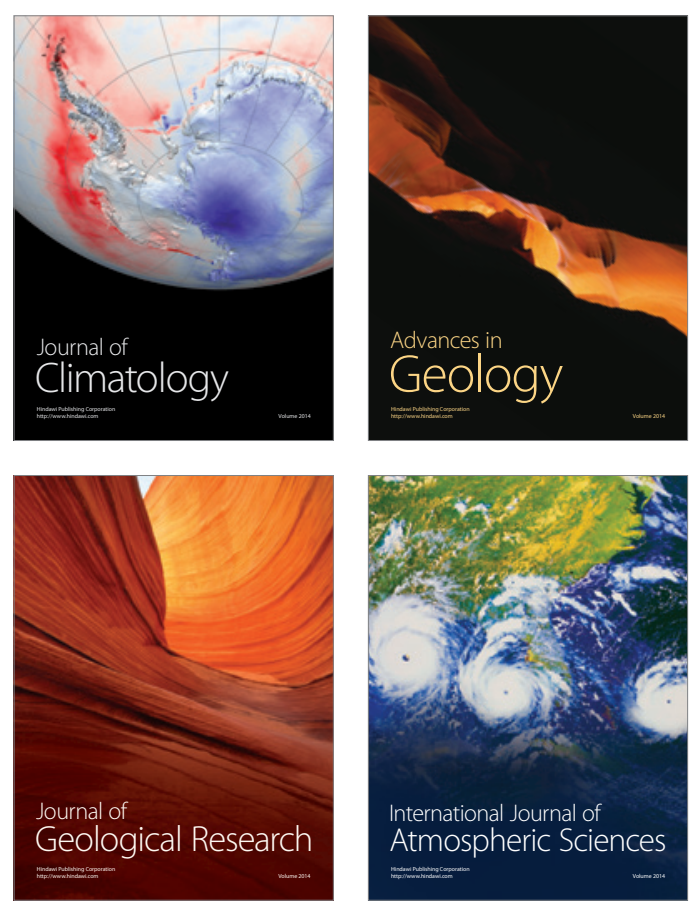
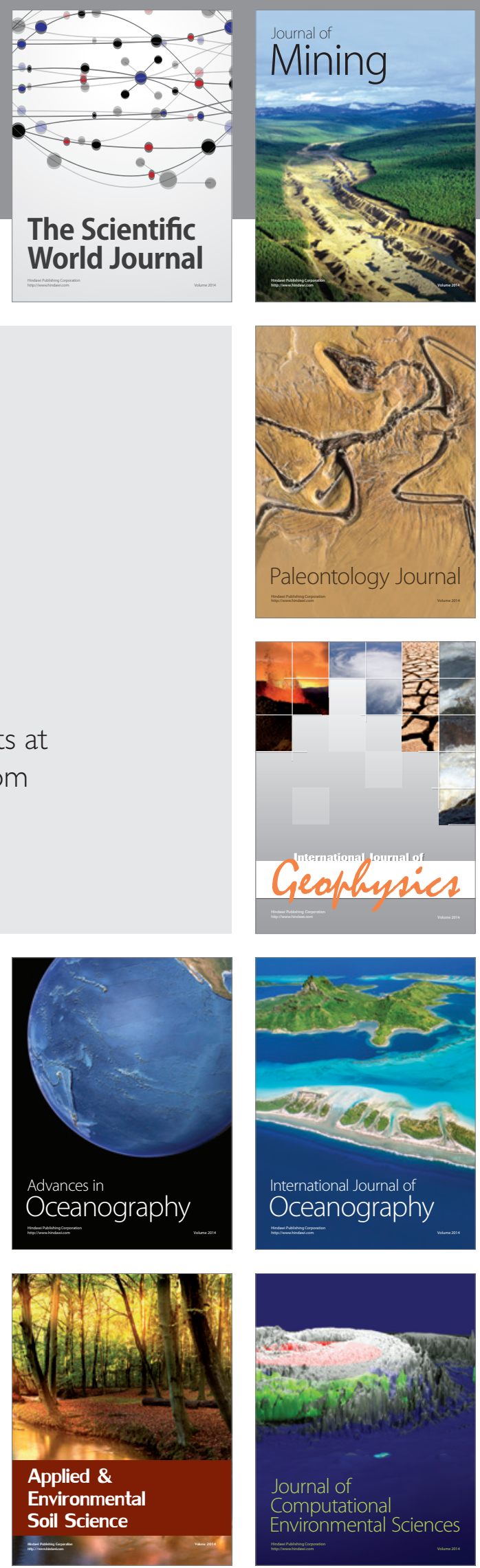